\title{
A STUDY ON SOLID WASTE MANAGEMENT AWARENESS AMONGST YOUNGSTERS OF MUMBAI
}

\author{
Dr. Devdatta Lad \\ Department of Zoology, \\ Wilson College, \\ Chowpatty, Mumbai - 400007
}

\author{
Mr. Rustam Chauhan \\ Department of Chemistry, \\ Wilson College, \\ Chowpatty, Mumbai - 400007
}

\author{
Ms. Pooja Gole \\ Department of Chemistry, \\ Wilson College, \\ Chowpatty, Mumbai - 400007
}

Article DOI: https://doi.org/10.36713/epra4115

\begin{abstract}
Solid waste management is the collection, treatment, and disposal of solid materials that are discarded by purpose or no longer useful. Improper disposal of solid waste result in unsanitary conditions which lead to pollution and spreads various infections and diseases. Solid waste management is one of the major challenges faced by many countries around the globe. Inadequate collection, recycling or treatment and uncontrolled disposal of waste in dumps can lead to severe hazards, such as health risks and environmental pollution. The present research survey clearly indicates that most of the youngsters are aware about the problem of the Solid waste management. They are also aware about the various soil and air pollution problems that arise due to the solid waste. The young generation clearly stated that because of the landfills there are serious health issues among the people that reside in the nearby areas. They know about the $3 R$ philosophy, dry and wet waste, cutting down the production of the solid waste is the solution on this aggravating problem, ban on plastic is important and segregation of non biodegradable and biodegradable waste has to be done. Many young participants are unhappy with the mode of working of the Municipal corporation in the city with respect to solid waste management. About $86 \%$ participants know about the Swachha Bharat Abhiyan and are willing to participate in such cleanliness campaign. The positive aspect of this study is that the youngsters are completely sensitized about the problems and issues related to Solid waste management. They are also ready to help and overcome such problems that are going to hamper the nature in the future. Indian Government must use such a sensitized workforce and must try to control the increasing problem of solid waste.
\end{abstract}

KEYWORDS: - solid waste, 3Rs, plastic bags, dry waste, wet waste, soil pollution.

\section{INTRODUCTION}

Solid waste management is the collection, treatment, and disposal of solid materials that are discarded by purpose or no longer useful. Improper disposal of solid waste result in unsanitary conditions which lead to pollution and spreads various infections and diseases. Solid waste management is one of the major challenges faced by many countries around the globe. Inadequate collection, recycling or treatment and uncontrolled disposal of waste in dumps can lead to severe hazards, such as health risks and environmental pollution.

The huge population of India is responsible for mammoth generation of MSW with daily rate of generation is $400 \mathrm{~g}$ per capita. The constituents of MSW mainly comprise of compostable items (51-53\%), followed by recyclable (17-18\%) and having a moisture content of $46.76 \%$. The MSW generated contains $\mathrm{C} / \mathrm{N}$ ratio approximately 32 with calorific value of about $1700-1800 \mathrm{Kcal} / \mathrm{Kg}$. Only fraction $(10-12 \%)$ of the total 
compostable waste was found to be used for composting. There are plenty of technologies available for generating energy and other useful substances from the MSW ecofriendly, but $60 \%-90 \%$ of MSW generated in cities and towns are directly disposed off on or into land in an unsatisfactory manner. (Rouf Ahmad Bhat, 2018)

The decomposition of waste into constituent chemicals is a common source of local environmental pollution. This problem is especially acute in developing nations. Very few existing landfills in the worlds poorest countries would meet environmental standards accepted in industrialized nations, and with limited budgets there are likely to be few sites rigorously evaluated prior to use in the future. The problem is again compounded by the issues associated with rapid urbanization. A major environmental concern is gas release by decomposing garbage. Methane is a by-product of the anaerobic respiration of bacteria, and these bacteria thrive in landfills with high amounts of moisture. Methane concentrations can reach up to $50 \%$ of the composition of landfill gas at maximum anaerobic decomposition. A second problem with these gasses is their contribution to the enhanced greenhouse gas effect and climate change. (Pervez Alam1 \& Kafeel Ahmade, 2013) Liquid leachate management varies throughout the landfills of the developing world. Leachate posses a threat to local surface and ground water systems. The use of dense clay deposits at the bottom of waste pits, coupled with plastic sheeting-type liners to prevent infiltration into the surrounding soil, is generally regarded as the optimum strategy to contain excess liquid. In this way, waste is encouraged to evaporate rather than infiltrate. (Royal Commission Report 1984)

The main purpose of the present research survey is to determine the solid waste management awareness amongst the college youngsters of Mumbai region.

\section{MATERIAL AND METHODS}

The present study was conducted through the medium of a questionnaire, circulated among youngsters within age group ranging from 18 to 25 years. All over 100 youngsters response to the questionnaire was recorded. The responses collected were analyzed and inferences were drawn based on the analysis.

The Questionnaire was as follows: -

1) What is done to the garbage collected at dump yards.

2) How is environment affected due to improper solid waste management.

3) Which section of society is most affected due to formation of dumps and how.
4) What is 3Rs philosophy of solid waste management as per you.

5) What is the amount of garbage generated from your house per day (in $\mathrm{Kgs}$ approximately)

6) How can/will cut down the amount of garbage generated at your house or commercial establishment.

7) How often do you use Plastic bags.

8) How would you segregate waste.

9) How will segregation of waste will help in reducing waste.

10) Should the work of waste collection be given to NGOs.

11) Enlist five dry waste and five wet waste you know.

12) What is the aim of Swaccha Bharat Abhiyan.

13) Have you ever participated in any cleanliness campaign.

14) Would you like to participate in any programme/campaign.

15) Do you know any dumping ground nearby your area.

\section{RESULTS}

1) About $68 \%$ of the participants said that the garbage collected is segregated and further steps like decomposition and recycling is done by the municipal bodies. Burning of the garbage is done to reduce its size, was answer of $18 \%$ of the participants. $13 \%$ of participants said that the garbage is used for the landfill. While $1 \%$ of the people had no idea about what happens to the garbage collected at dump yards.

2) When asked about the adverse effect of improper solid waste management on environment, $81 \%$ said that improper method of solid waste management can pollute air, water, soil and can cause harm to animal life. Remaining $19 \%$ had no opinion on this.

3) The creation of the dumping ground generally affects the economically poor section of the society. In metropolis like Mumbai affording a house at good place is expensive. Thus people who can't afford them has to compromise to slums built near dump yards. This risks their health due to improper sanitation over the place. This was the opinion of all the youngsters.

4) When asked about, 3R philosophy of the solid waste management, $72 \%$ of the total 
participants knew about this while $28 \%$ were completely unaware of the $3 \mathrm{R}$ philosophy.

5) An approximate weight of solid waste generated per day was asked to the volunteers in kilograms. $27 \%$ answered it as less than 1 $\mathrm{kg}$ per day; while $63 \%$ mentioned it was ranging from 1 to $5 \mathrm{kgs}$ of solid waste per day.

6) The generation of the domestic waste must be cut down in order to reduce the overall generation of the solid waste and thus when asked for the solution for the same; $50 \%$ of total participants suggested that cutting the total consumption of waste producing goods may help. $22 \%$ suggested making composite pit to make fertilizer out of the total biodegradable waste. And the rest $28 \%$ suggested of segregating the waste and using eco -friendly materials.

7) Plastic has been one of the major contributor to the pollution of soil, water and blockage in drainage causing other management problems. $76 \%$ participants agreed of using plastic bags on their daily basis. $22 \%$ wrote that they don't use plastic bags.

8) About $92 \%$ participants answered that they would segregate waste as biodegradable and non biodegradable. While $8 \%$ had no clue about segregation of the waste.

9) Similarly $92 \%$ participants responded that the segregation of the waste would help in reduction of waste accumulation as biodegradable waste would be decomposed rather than compilation. While $8 \%$ had no clue about segregation of the waste.

10) Collection of the garbage is one among the major task municipal corporation performs. When asked about the work of collection of garbage be handed over to NGO's, $59 \%$ of people agreed and $41 \%$ of people totally disagreed on this. This may be taken as the unhappiness of $59 \%$ toward working efficiency of municipal corporation.

11) As many as $90 \%$ percent participants were able to enlist 5 dry waste and wet waste. $10 \%$ were not able to enlist dry and wet waste. Some of the examples given by the participants are as follows: - Dry waste: Plastic, Wood, Glass, Metal items, Clothing etc. and Wet waste: - Vegetable peels, Fruits peels, Coconuts shells, Egg shells, Used leaves and flowers.

12) Swachha Bharat Abhiyan was launched by central government in 2014, by Prime minister Shri Narendra Modi. The campaign aims to clean up streets, roads and infrastructure of India's cities and villages. In order to know about how successful the campaign has been and how many of our participants know about it, we asked the aim of the campaign around 86 $\%$ of the participant knew about and rest had unclear idea.

13) There has been many cleanliness campaign conducted since the launch of the Swachha Bharat Abhiyan. Many NGO's have been actively campaigning for cleanliness programs. The participants were asked about the participations in any of such campaign. Almost $100 \%$ of the participants have participated or are been participating in various cleanliness campaign.

14) All the participants registered their willingness to participate in cleanliness drive.

15) All the participants had no idea about any dumping ground nearby their area.

\section{CONCLUSION AND DISCUSSION}

Perla R Bautista in 2019 conducted study on level of awareness and practices on solid waste management (SWM) among college students. Gathered data were analyzed and interpreted using descriptive and inferential statistics. The findings of the study showed that the students are aware of the solid waste management (SWM). Most of them were aware of the policies and management of SWM but relatively not aware of their roles as students in the implementation of SWM.

Margarita C. Paghasian in 2017 did a descriptive correlation research with 253 randomly- selected college students. It employed an adopted questionnaire concerning the awareness of solid waste management of the students and their practices. Data were gathered, analyzed and interpreted using the frequency and percentage distribution and chi-square test. Findings showed that the awareness on solid waste management of the students was high; their practices in terms of segregation, reduce and recycle were good; and their practices in terms of recycle and disposal were fair. The awareness on solid waste management of the students had no influence on their practices in terms of disposal however their awareness had affected their practices specifically on segregation, reduce, reuse, and recycle.

Hussein I. Abdel-Shafya Mona, S. M. Mansourb (2018), Disposal of solid wastes is a stinging and widespread problem in both urban and rural areas in many developed and developing countries. Municipal solid waste (MSW) collection and disposal is one of the major problems of urban environment in most countries worldwide today. MSW management solutions must be 
financially sustainable, technically feasible, socially, legally acceptable and environmentally friendly. Solid waste management issue is the biggest challenge to the authorities of both small and large cities. Valorization of food organic waste is one of the important current research areas. The conventional landfill, incineration, composting, and ways of handeling solid wastes are common as mature technologies for waste disposal. Traditionally, the most commonly used technologies for the treatment and valorization of the organic fraction of MSW are composting and anaerobic digestion (AD). The generation of organic solid waste (OSW); worldwide; is dramatically increasing each year. Most of the OSW's are composed of agricultural waste, household food waste, human and animal wastes, etc. They are normally handled as animal feed, incinerated or disposed to landfill sites. OAW's are comprised of materials rich in proteins, minerals, and sugars that could be used in other processes as substrates or raw materials.

The present research survey clearly indicates that most of the youngsters are aware about the problem of the Solid waste management. They are also aware about the various soil and air pollution problems that arise due to the solid waste. The young generation clearly stated that because of the landfills there are serious health issues among the people that reside in the nearby areas. They know about the 3R philosophy, dry and wet waste, cutting down the production of the solid waste is the solution on this aggravating problem, ban on plastic is important and segregation of non biodegradable and biodegradable waste has to be done. Many young participants are unhappy with the mode of working of the Municipal corporation in the city with respect to solid waste management. About $86 \%$ participants know about the Swachha Bharat Abhiyan and are willing to participate in such cleanliness campaign. The positive aspect of this study is that the youngsters are completely sensitized about the problems and issues related to Solid waste management. They are also ready to help and overcome such problems that are going to hamper the nature in the future. Indian Government must use such a sensitized workforce and must try to control the increasing problem of solid waste.

\section{REFERENCES}

1. Hussein I. Abdel-Shafya Mona, S. M. Mansourb, (2018), Solid waste issue: Sources, composition, disposal, recycling, and valorization, Egyptian Journal of Petroleum Volume 27, Issue 4, December 2018, $1275-1290$.

2. Margarita C. Paghasian, (2017), Awareness and Practices on Solid Waste Management among College Students in Mindanao State University Maigo School of Arts and Trades. Advances in
Social Science, Education and Humanities Research, Volume 128, 5- 12.

3. Perla $R$ Bautista, (2019), Level of awareness and practices on solid waste management (SWM) among college students. J. Bio. Env. Sci. 14(1), 131-138.

4. Pervez Alam1 \& Kafeel Ahmade, (2013) Impact of Solid Waste on Health and The Environment. Special Issue of International Journal of Sustainable Development and Green Economics (IJSDGE), Volume - 2, I-1, 165.

5. Rouf Ahmad Bhat, Shabeer Ahmad Dar and Davood Ahmad Dar, (2018) Municipal Solid Waste Generation and current Scenario of its Management in India. International Journal of Advance Science and Engineering, Volume No. 07, 419-431.

6. Royal Commission on Environmental Pollution, (1984) 10th Report tackling pollution -experience and prospects London: HMSO. 